\title{
Replication characteristics and core size of intranuclear herpes simplex virus (HSV-1) in genital skin lesions: electronmicroscopy studies of a biopsy from a female patient
}

\author{
J. BODDINGIUS, H. DIJKMAN, W. van der MEIJDEN, ${ }^{*}$ P. SCHMITZ,† T. van JOOST, and \\ E. STOLZ*
}

Department of Dermato-Venereology Research Laboratory, ${ }^{*}$ the Department of Dermato-Venereology of the Academic Hospital Dijkzigt, and TThe Institute of Biostatistics, Medical Faculty, Erasmus University, P.O. Box 1738, 3000 DR Rotterdam, The Netherlands

\begin{abstract}
Summary. Herpes simplex virus (HSV) type 1 genital infection, leading to ulcerating lesions in a female patient, was studied by electronmicroscopy. Infection had probably been recent, through oro-genital contact with a cold sore on the husband's lip. Cellculture typing and serological tests indicated that the patient currently had an HSV-1 secondary infection. Aspects studied in a skin biopsy from an ulcerating labium majus were epidermal cell types infected, stages in virus genesis, virus core diameter in intranuclear capsids and extracellular appearance of virus. Different stages in virus genesis, in virus envelope formation and in nuclear and cytoplasmic degeneration were observed in the few remaining, rounded and swollen, epidermal (?) spinosum cells. Their nuclei, some with marginated chromatin, harboured besides dense-cored or empty capsids, electron-dense blobs possibly representing clones of immature virus and falling apart into aggregates of small granules. In other nuclei, large clusters of dense-cored capsids, some distinctly hexagonal in shape, had accumulated in wide gaps in the nuclear membrane whereas remaining nuclear membrane portions were quadruple and often engaged in viral envelope formation. Partially enveloped capsids and naked dense-cored capsids were seen extracellularly indicating their survival outside cells. An occasional virion was present in dermal blood vessel lumina. Measurements of the electron-dense core (nucleoid) of intranuclear capsids in electronmicrographs showed that the HSV-1 core diameter differs very significantly from the core of intranuclear HSV-2 capsids, thus allowing a clear distinction by electronmicroscopy between the two HSV subtypes in plastic-embedded biopsies.
\end{abstract}

\section{Introduction}

Herpes simplex virus type 1 (HSV-1), a karyotropic dermato-tropic and facultatively neurotropic DNA virus, causes recurrent papular and vesicular eruptive lesions on epithelia at mucocutaneous borders and on the oral mucosa, whereby lips, oropharynx, eyes or the face are involved. Rarely, the virus causes encephalitis.

In the last decade, genital HSV-1 lesions have been reported. In females, the infection is considered to originate from oro-genital contact with partners who have oral HSV-1 lesions (Evrard, 1974; Whitney et al., 1978), to be of unknown origin

Received 7 May 1986; revised version accepted 20 Sep. 1986. but acquired after sexual intercourse (Kawana t al., 1982; Kit et al., 1983) or to occur in virgins whence diagnosed as progenital herpes (Ishiguro $e t$ $a l .$, 1982). There are reports of genital HSV-1 in females and males (Kawana et al., 1976; Smith et al., 1976; Reeves et al., 1981; Peutherer et al., 1982), of the simultaneous presence of HSV-1 and HSV-2 in the human body (Maekawa et al., 1981), and of the occurrence of sequential HSV-1 and HSV-2 infections in genital organs (Kit et al., 1983). The rate of recurrent genital infections seems to be lower for HSV-1 than for HSV-2 (Reeves et al., 1981). Type-specific drugs have been developed (DeClercq et al., 1979, 1980).

There have been electron-optical investigations of HSV-1 and of its mutants in cell cultures (Epstein, 
1962; Ciampor and Szanto, 1982; Dargan and Subak-Sharpe, 1983; Addison et al., 1984) and of purified nucleocapsids by immuno-electronmicroscopy (Vernon et al., 1981). There have been no electronmicroscopy studies on HSV-1 capsids and virions in biopsies of genital lesions.

In the ultrastructural work presented here, different microscopically-detectable intranuclear structures reminiscent of various stages in virus genesis were investigated as well as features of virus envelope formation, dimensions of the virus core, and the location of virus or virions extracellularly in the epidermis or dermis in acute, ulcerating, genital HSV-1 skin lesions in a female patient.

\section{Patient and methods}

\section{Clinical details}

A female patient (white European, $27 \mathrm{y}$, married, housewife) had suffered for 6 days from increasing vulval pain, particularly during micturition, washing and on touching. There was no previous history of genital disorders or of virus diseases other than verrucae plane on the left arm $5 \mathrm{y}$ before. Recent treatment by her general practitioner had included miconazole ointment and oral doxycycline and metronidazole which had been unsuccessful. Examination revealed extensive ulcerations on the labia majora and minora (fig. 1), perineum and peri-anal skin. Inguinal lymph glands were enlarged and tender bilaterally.

A preliminary diagnosis of herpes genitalis was made, based on clinical manifestations, a probable source of recent infection (the patient's husband who did not suffer from genital disease but had a cold sore on his lip and had had oro-genital contact with his wife in the week before her lesions had appeared; when the patient was admitted, a crusted lesion still could be seen on the husband's lip), and dark-field examination of vulval smears and, later, vulval cultures and serological tests, results of which were negative for Treponema pallidum, gonococci and other sexually-transmitted organisms.

Samples for vulval HSV cultures, for the Tzanck test on a vulval ulcer, and blood for serological HSV tests were taken on the first day of admission. Vulval cultures revealed HSV-1 (Virological Laboratory, Municipal Health Department, Rotterdam). The Tzanck test showed atypical cells (but insufficient indications of malignancy), reactive changes (i.e., slight dysplasia due to inflammation) and a vaginal flora consisting predominantly of the virus. Serum sampled 6 days after the onset of symptoms (i.e., c. 8-13 days after genital infection with the virus, the incubation time of HSV-1 being 2-7 days) was tested. No specific IgM was found in the serum (Virological Laboratory, Municipal Health Department, Rotterdam). The final clinical diagnosis, therefore, was secondary HSV-1 infection. Previous (subclinical) genital infection from a cold sore of the husband is unlikely, and

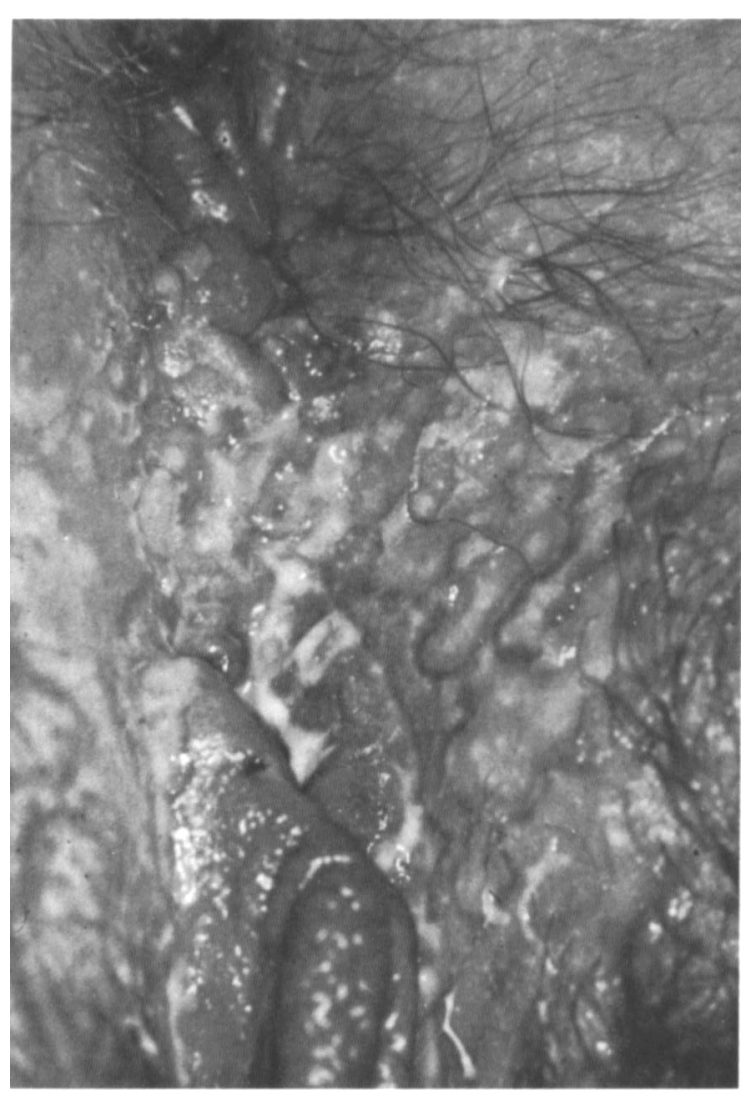

Fig. 1. Ulcerating genital skin lesion of a 27 -y-old female with a one-week history of HSV-1 infection probably contracted by oro-genital contact.

we surmise that primary infection may have occurred in childhood.

Under local anaesthesia, a skin biopsy was taken from an ulcerating lesion on a labium majus on the day of admission. The biopsy included clinically normal skin.

\section{Electronmicroscopy}

Within seconds of its excision, the skin biopsy was placed in a drop of GA/SPB fixative (see below) on a dental wax plate and divided with a fresh razor blade into four segments. After further fixation for $2 \mathrm{~h}$ in glutaraldehyde (GA) $3 \%$ in sucrose $(5 \%$ ) phosphate buffer

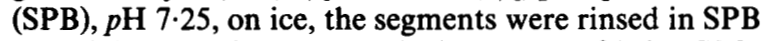
overnight, postfixed for $2 \mathrm{~h}$ in $\mathrm{OsO}_{4} 1 \%$ in $\mathrm{SPB}$, dehydrated in graded alcohols (increasing with steps of $10 \%, 10 \mathrm{~min}$ each) contrasted in block for $45 \mathrm{~min}$ with uranylacetate (saturated solution in absolute alcohol) and transferred via epoxypropane to Araldite.

Semi-thin $(1 \mu \mathrm{m})$ sections, stained with toluidin blue and basic fuchsin, were examined and photographed with a Leitz Ortholux microscope fitted with an Orthomat camera. Ultrathin sections, contrasted with uranylacetate 
and Reynold's lead citrate, were examined with a Philips EM 300 electronmicroscope.

Measurements of capsid and core diameters were made on electronmicrographs taken at the highest feasible microscope magnification. For the calculation of exact micrograph magnifications, a reference grid was photographed (Fulham $1002 \times$ shadow cast crossed lines carbon grating replica; 2160 lines $/ \mathrm{mm}$ ).

\section{Results}

Clinically normal skin. In the papillary dermis there was massive cellular infiltration. In the epidermis there were intracellular vacuoles and some infiltrating cells in the basal layer. Widened intercellular spaces with abounding desmosomal fragments and aggregates, possibly of ribosomes, were seen in the stratum spinosum. Neither capsids nor virions were seen.

Ulcerating skin. There was complete destruction of the normal epidermal architecture, with extensive necrosis. Only a few stratum corneum cells remained apically, and rounded, possibly spinosum, cells described in detail below were dispersed amongst abounding cellular debris that included thick curved bundles of tonofilaments (fig. 2a). Lymphocytes were amongst the many infiltrating cells.

The rounded and swollen cells mentioned above with ballooning nuclei (fig. $2 \mathrm{a}, \mathrm{b}, \mathrm{c}$ ) showed nuclear and cytoplasmic changes connected with virus infection and propagation.

By electronmicroscopy, marginated chromatin was seen in some of the nuclei with electron-dense round inclusions, aggregates of small granules, agglomerations of larger granules and dispersed virus capsids (fig. 3a). The disintegrating cytoplasm lacked tonofilaments. In other, larger, more distinctly ballooning nuclei, chromatin was not marginated and there were clustered and dispersed capsids. Nuclear membranes locally were reduplicated and occasionally involved in virus envelope formation, and a thick band of tonofilaments closely surrounded the nucleus (figs. $3 \mathrm{~b}, 4,5$ ).

In more detail, the nuclear and cytoplasmic changes connected with virus propagation were as follows:

(1) Margination of chromatin (fig. 3a) in nuclei lacking clearly outlined or reduplicated membranes.

(2) Electron-dense round inclusions or blobs (figs $3 \mathrm{a}, \mathrm{b}, 4 \mathrm{a})$ measuring $0.35-0.65$ micron in diameter in varying numbers and sometimes quite evenly spread, as if in "strategic positions", throughout the nucleoplasm (fig. 4a). On their surface, the inclusions often had a corona of small blebs and nearby were rounded structures with a clear centre and a rim of radially arranged short arrays (fig. 3b) also seen in fully grown dense-cored virus capsids (figs. 4c, 5b). Some inclusions were falling apart into granular structures (fig. 3a, stage 2).

(3) Small granules $22-30 \mathrm{~nm}$ in diameter (fig. 3a, stage 3) besides small aggregates of larger granules $40 \mathrm{~nm}$, in diameter (fig. 3a, stage 4), particularly in blob-containing nuclei with marginated chromatin.

(4) Virus capsids in the nucleoplasm with a round electron-dense core (figs $3 b, 4 c$ ) and sometimes an electron-translucent centre (fig. 5b). The virus capsids were often hexagonal (fig. 4c). There were some empty vesicles of capsid size (figs 4c, $5 b)$. Measurements of the diameter of round electron-dense cores in intranuclear capsids were made on photomicrographs of cores taken at the highest feasible electronmicroscope magnification. The frequency distribution of the diameters is illustrated in fig. 6. The average diameter of the HSV-1 core was $39.8 \mathrm{~nm}(\mathrm{SD} \sigma=3.5473 ; \mathrm{n}=100)$. The diameter of the virus capsid proper averaged $78 \mathrm{~nm}(\mathrm{SD} \sigma=5.5939 ; \mathrm{n}=100$; frequency distribution shown in fig. 7).

(5) Nuclear membranes reduplicated in ballooning nuclei. Three phases of what we consider to be capsid passage through, and envelope formation by, the inner nuclear membrane were seen. (i) Nidation of the capsid in the inner double nuclear membrane. At the place of contact the membrane had become electron-dense and thickened and represented now the future inner coat of the virus envelope (fig. 4c, stage 1). A virus core is not detectable in the figure. (ii) Closure of the inner nuclear membrane above the enveloped capsid (fig. $4 c$, stage 2). (iii) The capsid "floated" in the space between the (double) nuclear membranes, the electron-dense inner coat was broadened, the virus core was very electron-dense (fig. $4 \mathrm{c}$, stage 3 ). Fine structures radiated from the core and extended into the inner coat. Envelope formation not being a frequent phenomenon in our preparations, only a few partly enveloped virus particles were seen in the cytoplasm (fig. 4b). Naked dense-cored capsids or empty vesicles often embedded in tonofilaments were seen more often (fig. 4c).

(6) Wide gaps in the nuclear membrane and clusters of naked virus capsids (fig. 4a) barred off by a thick zone of tonofilaments from the cytoplasm. Rounded intact or flocculent portions of electrondense blobs (above) were also present in or near these gaps (fig. 3b). When gaps were very wide, large clusters of naked capsids were seen "hanging" from the nucleus like bunches of grapes from a vine tree (fig. 5a). 


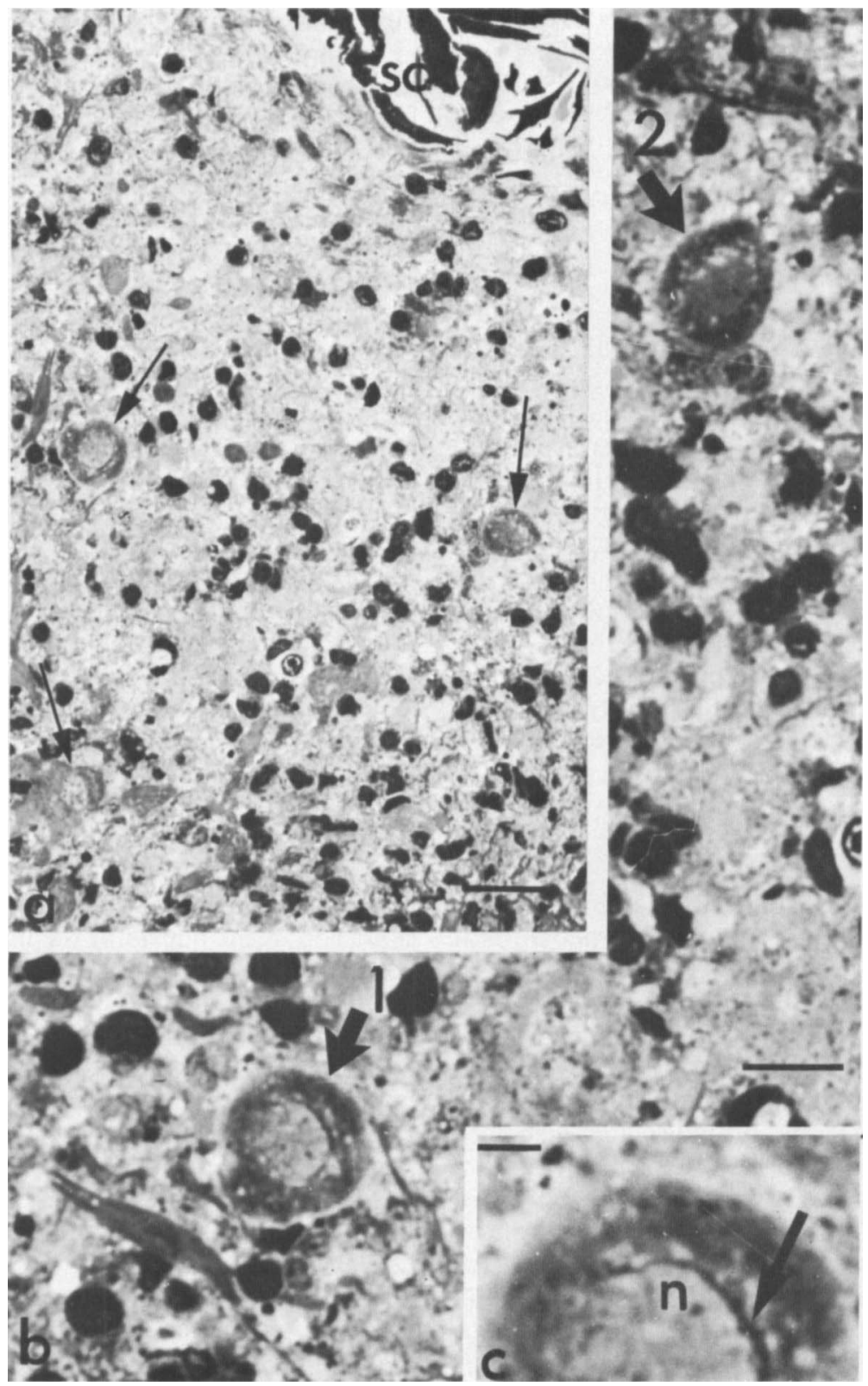

Fig. 2. (a). Epidermis of ulcerating lesion on a labium majus. Note apically a few stratum corneum cells ( $s c$ ) and, amongst numerous inflammatory cells, some dispersed rounded, possibly spinosum cells (arrows) which are enlarged in $(b)$ and $(c)$. Bar $=20 \mu \mathrm{m}$. Semithin section; toluidin blue-basic fuchsin staining. (b) Two rounded cells (thick arrows 1,2) with translucent nuclei lined by a thick nuclear membrane. Note dark dots, also depicted by electronmicroscopy in figs. 3 and 4 , in the nucleoplasm. Bar $=10 \mu \mathrm{m}$. Semithin section. (c) High magnification of cell 1 (b). The translucent nucleus $(n)$ is lined by a very thick (reduplicated) nuclear membrane (arrow). Bar $=3 \mu \mathrm{m}$. Semithin section. 

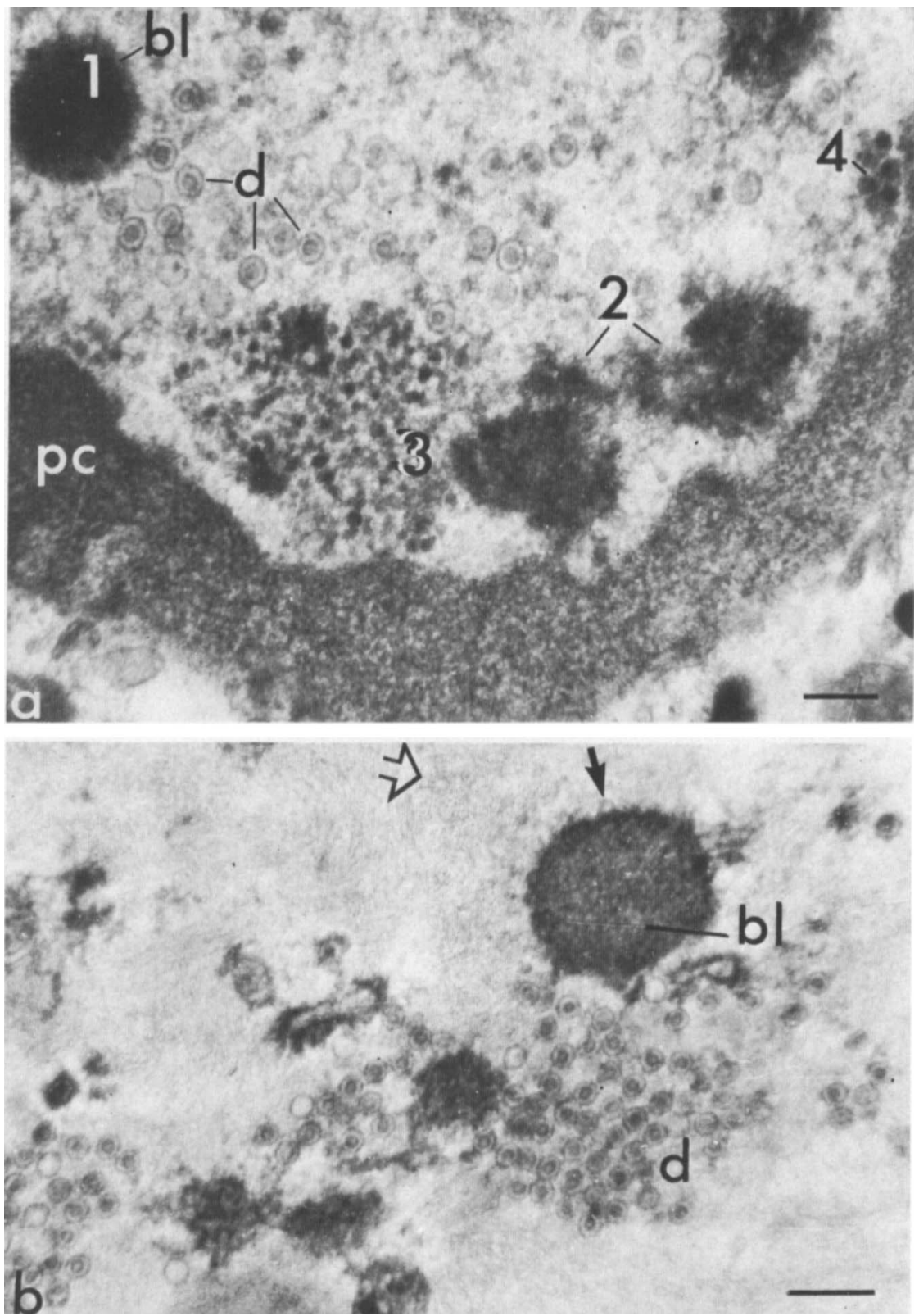

Fig. 3. (a) Virus propagation in nucleus with peripheral chromatin ( $p c$ ). Possible stages in capsid formation: (1) electron-dense inclusion or blob $(b l)$ possibly representing clones of immature virus; (2) falling apart of blobs; (3) segregation into individual 2230-nm granules; (4) growth into $40-\mathrm{nm}$ granules. Note mature naked dense-cored capsids $(d)$. Bar $=0 \cdot 2 \mu \mathrm{m}$. (b) Electron-dense inclusion or blob $(b l)$-in the centre of the blob packed rounded structures; at the periphery a corona of small blebs (dark arrow); nearby, rounded faint structures (open arrow) possessing a radially striped outer zone. Note, at (d), a cluster of dense-cored virus capsids. Bar $=0 \cdot 3 \mu \mathrm{m}$. 

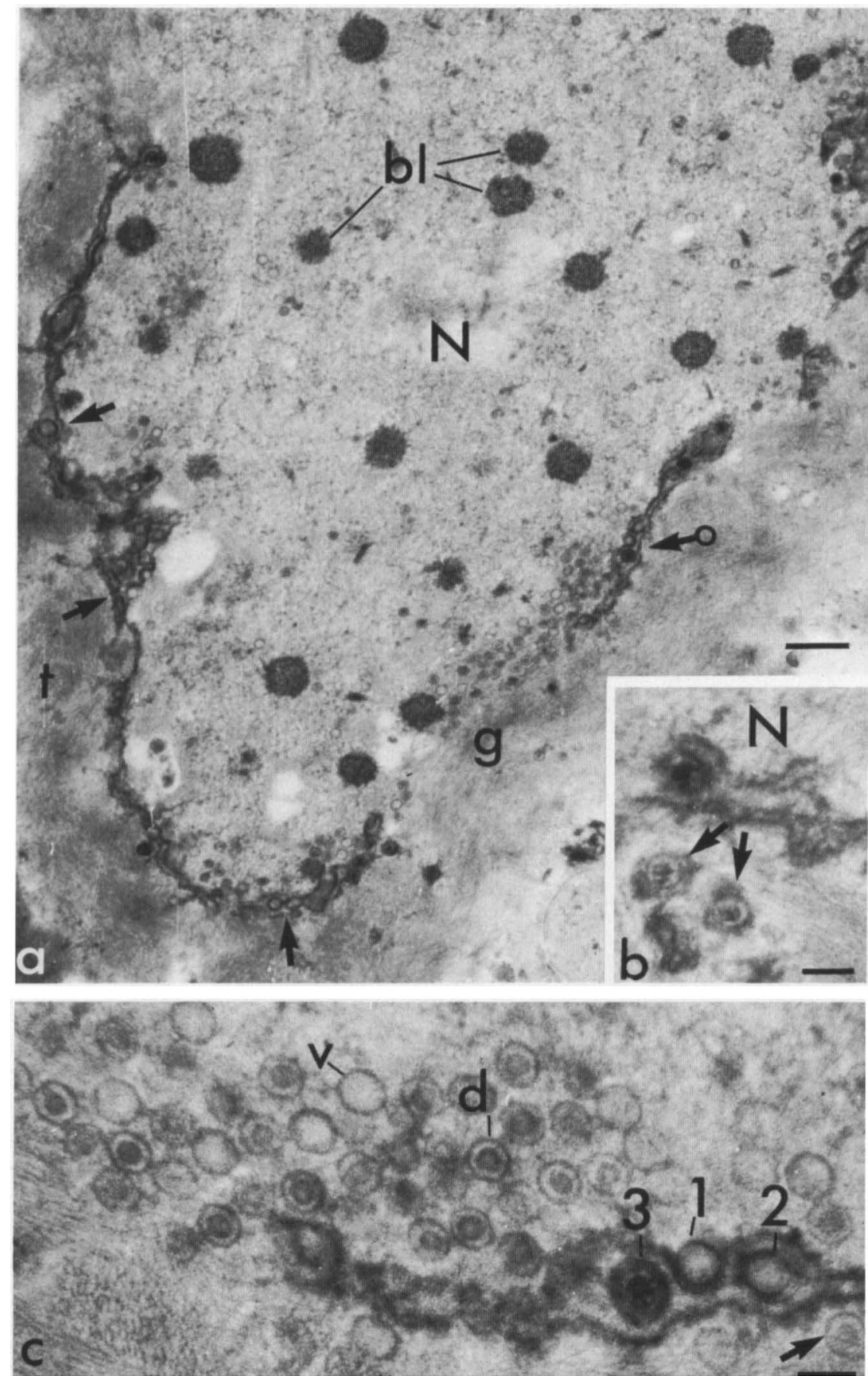

Fig. 4. (a) Electron-translucent nucleus $(N)$ harbouring electron-dense blobs $(b l)$ and clusters of HSV-1 dense-cored and some empty capsids near or in gaps $(g)$ in the nuclear membrane. Reduplicated nuclear membrane portions with capsid nidation and virus envelope formation are indicated by arrows. Note tonofilament bands $(t)$ closely surrounding the nucleus. Bar $=0 \cdot 5 \mu \mathrm{m}$. (b) Partly enveloped virus in the cytoplasm (arrows) close to nucleus $(N)$. Bar $=0 \cdot 1 \mu \mathrm{m}$. (c) Area $\leftarrow \circ$ in (a) shown in high magnification. Three possible stages $(1,2,3)$ of virus envelope formation by the inner of the reduplicated nuclear membranes are depicted. Note hexagonal dense-cored capsid $(d)$ and empty vesicles $(v)$. Naked dense-cored capsids $(\leftarrow)$ and empty vesicles are also present in perinuclear tonofilament bands. Bar $=0 \cdot 1 \mu \mathrm{m}$. 

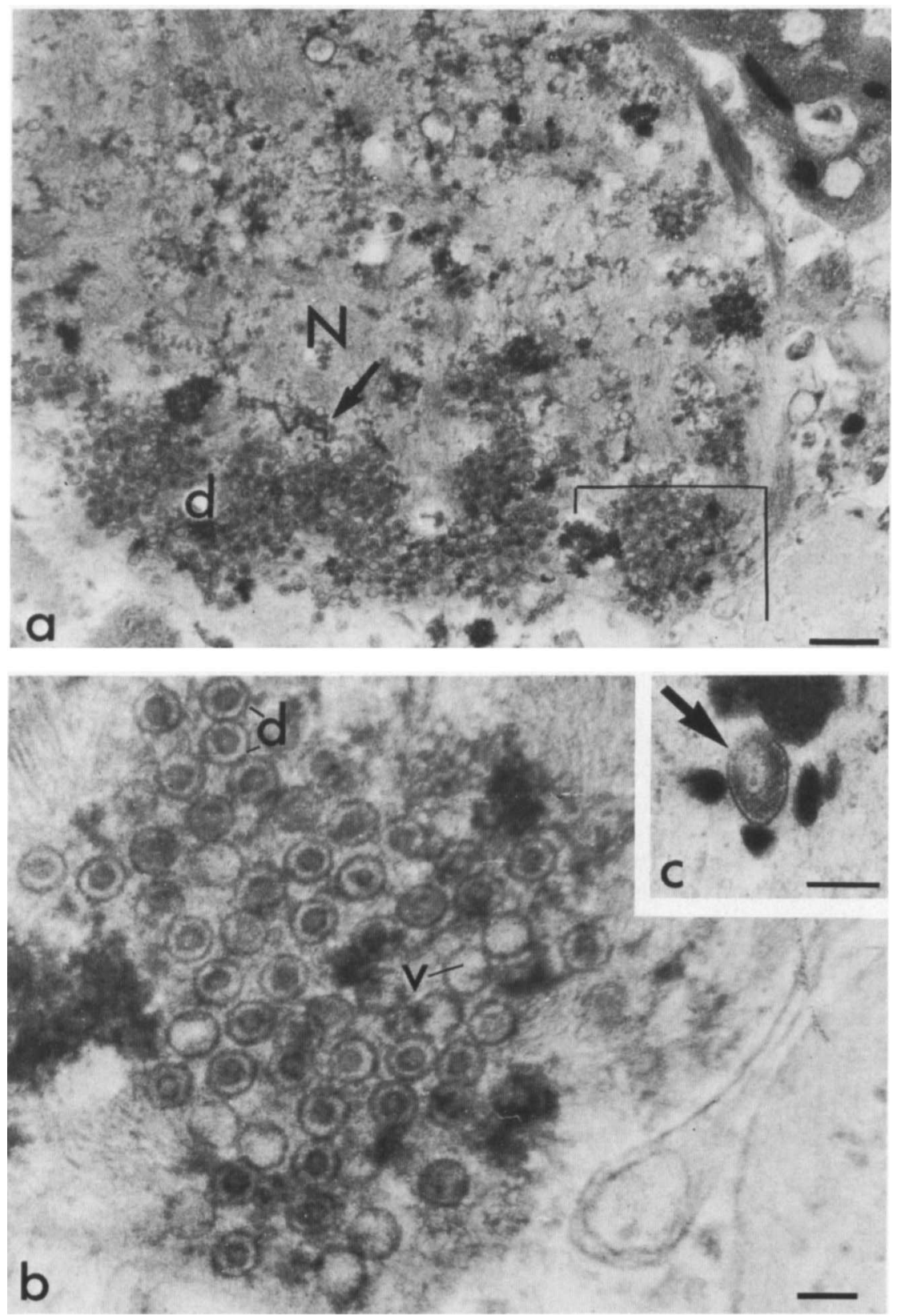

Fig. 5. (a) Clusters of dense-cored capsids $(d)$ occurring in or protruding through nucleus $(N)$, like bunches of grapes, into the cytoplasm. Note fragments of nuclear membrane (arrow) and ragged remainders of blobs. Bar $=0.5 \mu \mathrm{m}$. (b) Area outlined to the lower right in (a), at higher electronmicroscope magnification showing clusters of HSV-1, generally with an electron-dense core (d), a few empty vesicles $(v)$ and ragged remainders of blobs. Note the radially arranged zone around the core, the hexagonal shape of diameter of HSV-1 capsids located within nuclei of epidermal $\operatorname{Bar}=0 \cdot 1 \mu \mathrm{m}$. 


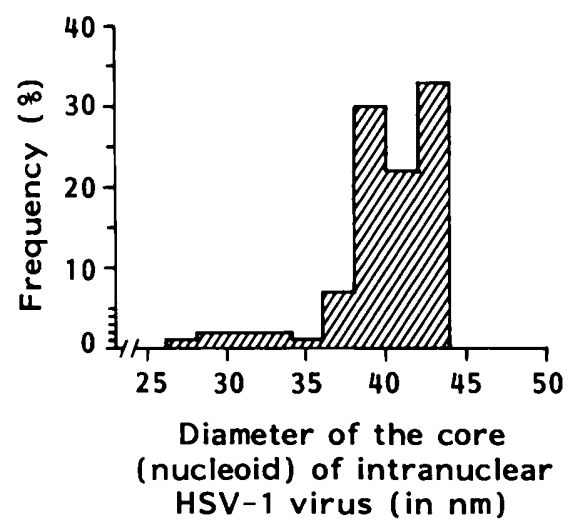

Fig. 6. Frequency distribution (in $\mathrm{nm}$ ) of the core (nucleoid) diameter of HSV-1 capsids located within nuclei of epidermal cells. Class width $2 \mathrm{~nm}$. Mean value of the core diameter $=39.8 \mathrm{~nm}$.

(7) Indistinctness of the cell membrane and its possible contribution to envelope formation. Extracellular virus particles, some possessing part of a virus envelope, were embedded in tonofilament bundles. More often, though, large clusters of naked capsids were found amongst cell debris.

(8) Absence of true virions in the ulcerating epidermis but virion-like inclusions intraluminally in dermal blood vessels (fig. 5c).

(9) Abnormal dermal nerves, particularly their myelinated fibres, without virions or capsids in them.

(10) Blood vessels in the dermis underlying the ulcerating epidermis showing characteristic features of inflammation (Boddingius et al., 1980), i.e., luminal and abluminal endothelial protrusions, fenestrations in or local disappearance of the endothelium with only the basal lamina remaining, and nuclear and cytoplasmic debris intraluminally.

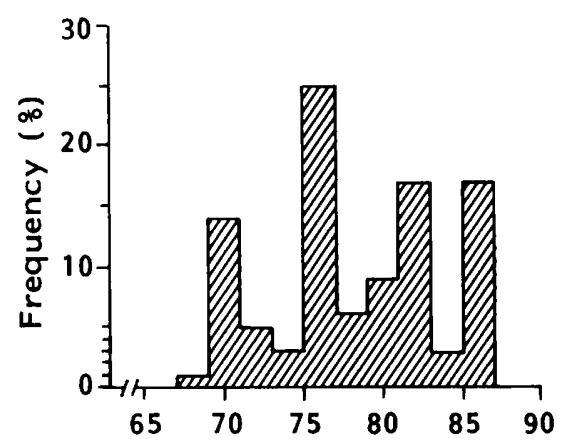

\section{Diameter of intranuclear HSV- 1 virus particles (in $\mathrm{nm}$ )}

Fig. 7. Frequency distribution (in $\mathrm{nm}$ ) of the diameter of whole HSV-l capsids in nuclei of epidermal cells. Class width $2 \mathrm{~nm}$. Mean value of the capsid diameter $=78 \mathrm{~nm}$.

\section{Discussion}

Studies on HSV infections are of importance because, in the last decade, possible associations have been revealed between HSV-1 infection and the occurrence of oral cancer (Shillitoe et al., 1983, 1984; Hirsch et al., 1984; Scully and Ward-Booth, 1984), brain tumours (Hadfield et al., 1984), Kaposi's sarcoma (Dotz and Berman, 1983), myelogenous leukaemia or other haematological malignancies (Lam et al., 1981), hairy cell leukaemia (Pozner et al., 1978), Burkitt's lymphoma (Stewart et al., 1965; Vernon et al., 1981) and histiocytic lymphoma (Salomon et al., 1982). Detection of virus antigen production can aid in monitoring mutations in cell metabolism (Campisi et al., 1983; Mayman and Nishioka, 1985).

The only study of fresh biopsies of HSV lesions by light microscopy and electronmicroscopy concerned herpes oesophagitis (Bürrig et al., 1984). Their illustrations and data on the virus core diameter $(38 \mathrm{~nm})$ indicate an $\mathrm{HSV}-1$ infection. Genital HSV-1 lesions have not hitherto been investigated by electronmicroscopy.

Our present studies have shown by electronmicroscopy that the rounded epidermal cells with swollen translucent and slightly dotted nuclei seen by light microscopy were the main virus-containing cells in ulcerating genital skin. Two kinds of viruscontaining nuclei were seen. We believe that nuclei possessing marginated chromatin, blobs and granules represent an earlier phase of virus propagation, subsequently "frozen" by necrotic processes, than do the ballooning nuclei with reduplicated membrane fragments in which virus propagation and envelope formation have proceeded further. The dots (above) in the nucleus were round electrondense inclusions $(0.35-0.65 \mu \mathrm{m})$ probably the same as the spherical bodies seen intranuclearly in wild HSV-1 infected tissue-culture cells by Dargan and Subak-Sharpe (1983) and held by them to be fragments of disorganised nucleolus; an explanation that does not fit the inclusions which we have seen. They initially were round and were quite uniformly distributed throughout the nucleus; they were located close to small 22-30 nm granules and seemed to loosen up into such granules, particularly in nuclei with marginated chromatin. Therefore, we believe that the blobs represent an early stage in the propagation of HSV-1 capsids, in the process of which some flocculent residual material remains and is extruded, together with some of the blobs, through wide gaps in the nuclear membrane into the cytoplasm or extracellularly.

The 22-30-nm granule aggregates, possibly coun- 
terparts of $20-\mathrm{m} \mu(\mathrm{nm})$ aggregates described by Morgan et al. (1959), were found in the same area as the large electron-dense blobs (above). Because some of the virus capsids in the same nucleus had a 20-nm core, the 22-30-nm granules may represent a stage, in virus genesis, following that of the electron-dense blobs and preceding true virus capsid formation. Morgan et al. (1959) considered that the aggregates of granules represented templates for the sequential formation, at several foci, of virus. The $40-\mathrm{nm}$ granules seen by us might represent another intermediate stage. If this is so, it suggests that before attaining a virus "membrane", the core occasionally may increase further in size.

We suggest that virus escaped from the cell nucleus in the lesion examined, in two main ways. The first was by transmembranous passage through locally reduplicated nuclear membranes, with, in many cases, formation of part of the virus envelope from the inner nuclear membrane and by an increase in electron density, i.e., by maturation of the core (see also Toshima et al., 1967). The core in this stage (fig. 4, stage 3) resembles that depicted by Nahmias and Roizman (1973, fig. 1). The presence of naked virus capsids between the nuclear membranes and in the perinuclear tonofilament bands indicates that naked capsids may gain access to the cytoplasm without much involving or disrupting the nuclear membrane. Such viruses remain enclosed in tonofilament bands after disintegration of the nucleus and most of the cytoplasm in infected cells. They are seen as naked or partly enveloped capsids in the extracellular bands.

The second was through wide gaps in the nuclear membrane. Clusters of virus may leave in this way, possibly because the thick tonofilament band closely surrounding the nucleus prevents gradual access of single virus particles to the cytoplasm. The clusters may correspond to the "dissolving viral crystals" seen by Morgan et al. (1959). The tonofilament alterations seen in infected cells may reflect cytoskeletal changes underlying cytopathic effects and aiding in virus dissemination (Krempien et al., 1984).

Completion of virus envelope formation by nuclear or cell membrane (Toshima et al., 1967) was not observed in our preparations. Possibly because of the absence of intact cell membranes, fully enveloped infective virions seemed no longer to be formed extensively during the phase of skin ulceration examined but, earlier, this may have been a feature, a pattern suggested by finding virions in the lumina of dermal blood vessels. Cellculture studies have suggested that virus capsids not surrounded by envelopes are unstable and are destroyed in the cytoplasm (Morgan et al., 1959). However, naked capsids seen extranuclearly in the cytoplasm or extracellularly in the lesion examined by us seemed stable. According to Nahmias and Roizman (1973), a complete envelope is not necessary for infectivity.

Electronmicroscopy studies of the structure of HSV have been of untyped HSV in cell cultures (Morgan et al., 1959; Epstein, 1962) and in smears (Smith and Coleman, 1983), HSV-1 purified nucleocapsids by immuno-electronmicroscopy to identify specific polypeptides (Vernon et al., 1981), and HSV type-1 strains, including wild type and temperature-sensitive (ts) mutants, in infected cell cultures (Dargan and Subak-Sharpe, 1983; Addison et al., 1984). Illustrations of intranuclear HSV-1 by Toshima et al. (1967), Dargan and Subak-Sharpe (1983) and Addison et al. (1984) are similar to pictures of intranuclear HSV in our work. This similarity in structure, and subtyping by cell culture, confirms the identity of our virus as HSV-1. In electronmicrographs by Toshima et al. (1967) of cell lines from lymphoma of the liver in patients with Burkitt's lymphoma, the intranuclear capsids are similar to the capsids seen in our biopsy, i.e., slightly hexagonal capsids with a clear centre (figs $4 c$ and $5 b)$.

Few data on the dimensions of the virus core and of the whole virus capsid of HSV-1 have been published. Epstein (1962) gave a core (nucleoid) diameter of $35 \mathrm{~m} \mu(\mathrm{nm})$ for HSV (untyped) in osmium methacrylate preparations. Morgan et al. (1959) found that the core of virus capsids within one nucleus varied in size, shape and density; the core dimensions were in the range $20-40 \mathrm{~m} \mu(\mathrm{nm})$, some scattered virus having the largest core with a

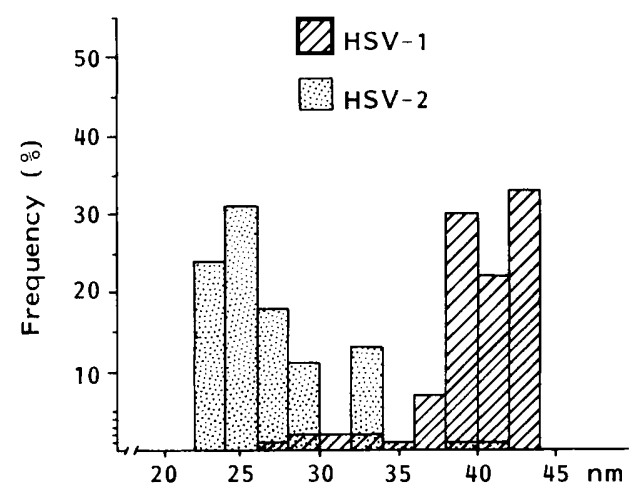

Fig. 8. Comparison of the core diameter of HSV-1 and HSV-2 intranuclear capsids in skin biopsies fixed and processed for plastic embedding by identical methods. Note that the HSV-1 core is significantly larger than the HSV-2 core. 
central region of diminished density. This is in full agreement with the frequency distribution that we found for the HSV-1 core diameter (fig. 6).

For measurements made by us on electronmicrographs taken at the highest possible magnification, the mean value for the diameter of the intranuclear virus capsid was $78 \mathrm{~nm}$ and of the core $39.8 \mathrm{~nm}$. In concurrent studies, the HSV-1 core diameter was found to differ very significantly $(p \ll 0.001)$ from

\section{REFERENCES}

Addison C, Rixon F J, Palfreyman J W, O'Hara M, Preston V G 1984 Characterisation of a herpes simplex virus type 1 mutant which has a temperature-sensitive defect in penetration of cells and assembly of capsids. Virology 138:246-259.

Boddingius J, Underdown R, Rees R J W 1980 Ultrastructural changes in blood vessels of peripheral nerves and of skin in leprosy patients. In: Latapi F (ed) Proceedings of the XIth International Leprosy Congress, Mexico 13-18 Nov 1978 (Excerpta Medica International Congress Series 466), Excepta Medica, Princeton.

Boddingius J, Dijkman H, van Joost T, van der Meijden W, Schift R, Stolz E 1984 Ultrastructure of type 1 and type 2 herpes simplex virus (HSV) infection of skin in genital regions. Ultramicroscopy 15: 393.

Bürrig K-F, Borchard F, Feiden W, Pfitzer P 1984 Herpes oesophagitis. II. Electron microscopical findings. Virchows Archiv A 404: 177-185.

Campisi J, Hafner J, Boorstein R, Pardee A B 1983 Hereditary orotic aciduria, Lesch-Nyhan syndrome and Xeroderma pigmentosum probed by herpes simplex virus: ${ }^{125}$ I-iododeoxycytidine incorporation as an assay for viral growth. Journal of Cellular Physiology 114:21-28.

Ciampor F, Szanto J 1982 Ultrastructural studies on the replication of herpes simplex virus in Pk and XTC-2 cells. Acta Virologica (Praha) 26:67-72.

Dargan D, Subak-Sharpe J H 1983 Ultrastructural characterization of herpes simplex virus type 1 (strain 17) temperature sensitive mutants. Journal of General Virology 64:13111326.

DeClercq E, Descamps J, DeSomer P, Barr P J, Jones A S, Walker R T 1979 (E)-5-(2-bromvinyl)-2'-deoxyuridine: A potent and selective anti-herpes agent. Proceedings of the National Academy of Science of the USA 76:2947-2951.

DeClercq E et al. 1980 Comparative efficacy of antiherpes drugs against different strains of herpes simplex virus. Journal of Infectious Diseases 141: 563-574.

Dotz W I, Berman B 1983 Kaposi's sarcoma, chronic ulcerative herpes simplex, and acquired immunodeficiency. Archives of Dermatology 119:93-94.

Epstein M A 1962 Observations on the fine structure of mature herpes simplex virus and on the composition of its nucleoid. Journal of Experimental Medicine 115 : 1-12.

Evrard J R 1974 Orogenital transmission of herpes simplex type 1. Obstetrics and Gynecology 44:593-595.

Hadfield M G, Murray B K, Thomson T A, Young H F 1984 Herpes virus type 1 serum antibodies and brain tumors in humans. Clinical Neuropathology 3: 68-71.

Hirsch J M, Johansson S L, Vahlne A 1984 Effect of snuff and herpes simplex virus-1 on rat oral mucosa: possible associations with the development of squamous cell carcinoma. Journal of Oral Pathology 13:52-62 the core diameter of intranuclear HSV-2 in identically fixed and embedded HSV-2 genital lesions (Boddingius et al., unpublished observation). The present finding of a significant difference in core diameter between HSV-1 and HSV-2 (fig. 8), which we have already reported (Boddingius et al., 1984), indicates that a clear distinction can be made between the two HSV subtypes by electronmicroscopy of plastic-embedded biopsies.

Ishiguro T, Ozaki Y, Matsunami M, Funakoshi S 1982 Clinical and virological features of herpes genitalis in Japanese women. Acta Obstetrica et Gynecologica Scandinavica 61:173-176.

Kawana T, Kawaguchi T, Sakamoto S 1976 Clinical and virological studies on genital herpes. Lancet 2:964.

Kawana T, Kawagoe K, Takizawa K, Chen J T, Kawaguchi T, Sakamoto S 1982 Clinical and virologic studies on female genital herpes. Obstetrics and Gynecology 60:456-461.

Kit $\mathrm{S}$ et al. 1983 Sequential genital infections by herpes simplex viruses type 1 and type 2 : restriction nuclease analyses of viruses from recurrent infections. Sexually Transmitted Diseases 10:67-71.

Krempien U, Jockusch B M, Jungwirth C 1984 Herpes simplex virus-induced cell surface protrusions. Intervirology 22: 156163.

Lam M T, Pazin G J, Armstrong J A, Ho M 1981 Herpes simplex infection in acute myelogenous leukemia and other hematologic malignancies. Cancer 48:2168-2171.

Maekawa M, Hino Y, Mori R, Hayashi Y, Oda H 1981 Differentiation of herpes simplex virus type 1 and type 2 by intranuclear tubular structures in clinical infection. Microbiology and Immunology 25:847-851.

Mayman B A, Nishioka Y 1985 Differential stability of host mRNAs in Friend erythroleukemia cells infected with herpes simplex virus type 1. Journal of Virology 53:1-6.

Morgan C, Rose H M, Holden M, Jones E P 1959 Electron microscopic observations on the development of herpes simplex virus. Journal of Experimental Medicine 110:643656.

Nahmias A J, Roizman B 1973 Infection with herpes-simplex viruses 1 and 2. New England Journal of Medicine 289:667674, 719-725, 781-789.

Peutherer J F, Smith I W, Robertson D H H 1982 Genital infection with herpes simplex virus type 1. Journal of Infection 4:33-35.

Pozner L H, Daniels C A, Cooper J A, Cohen H J, Logue G L, Croker B P 1978 Replication of type 1 herpes simplex virus in primary cultures of hairy cell leukemic leukocytes. American Journal of Pathology 90 : 187-199.

Reeves W C, Corey L, Adams H G, Vontver L A, Holmes K K 1981 Risk of recurrence after first episodes of genital herpes. Relation to HSV type and antibody response. New England Journal of Medicine 305: 315-319.

Salomon F, Sidi Y, Garfinkel D, Pinkhas J 1982 Severe herpes simplex infection in diffuse histiocytic lymphoma treated with adenine arabinoside. Dermatologica 165:215-217.

Scully C, Ward-Booth P 1984 Oral carcinoma: evidence for viral oncogenesis. British Journal of Oral and Maxillofacial Surgery 22:367-371.

Shillitoe E J, Greenspan D, Greenspan J S, Silverman S 1983 Immunoglobulin class of antibody to herpes simplex virus in patients with oral cancer. Cancer 51:65-71. 
Shillitoe E J, Greenspan D, Greenspan J S, Silverman S 1984 Antibody to early and late antigens of herpes simplex virus type 1 in patients with oral cancer. Cancer 54:266-273.

Smith I W, Peutherer J F, Robertson D H H 1976 Virological studies in genital herpes. Lancet 2:1089-1090.

Smith J, Coleman D V 1983 Electron microscopy of cells showing viral cytopathic effects in Papanicolaou smears. Acta Cytologica 27:605-613.

Stewart S E, Lovelace E, Whang J J, Ngu V A 1965 Burkitt tumor: tissue culture, cytogenetic and virus studies. Journal of the National Cancer Institute 34:319-327.

Toshima S, Takagi N, Minowada J, Moore G E, Sandberg A A
1967 Electron microscopic and cytogenetic studies of cells derived from Burkitt's lymphoma. Cancer Research 27 : 753771.

Vernon S K, Ponce de Leon M, Cohen G H, Eisenberg R J, Rubin B A 1981 Morphological components of herpes virus. III. Localization of herpes simplex virus type 1 nucleocapsid polypeptides by immune electron microscopy. Journal of General Virology 54:39-46.

Whitney J E, Skinner G R B, Buchan A 1978 Acquisition of type 1 herpes simplex vulvitis within a monogamous relationship. British Journal of Venereal Diseases 54:121123. 